\title{
CYCLIC AMP ENHANCING DRUGS MODULATE EICOSANOID RELEASE FROM HUMAN ALVEOLAR MACROPHAGES
}

Fred D. Beusenberg, Henk C. Hoogsteden*, Iván L. Bonta and Jan G.C. van Amsterdam

Department of Pharmacology, Faculty of Medicine, Erasmus University Rotterdam, P.O. Box 1728, 3000 DR Rotterdam, The Netherlands.

*Department of Pulmonology, University Hospital Dijkzigt, Dr. Molewaterplein 40, 3015 GD Rotterdam, The Netherlands.

(Received in final form February 7, 1994)

\section{Summary}

The effect of the phosphodiesterase inhibitor isobutyl-methylxanthine (IBMX), salbutamol and sodium nitroprusside was evaluated regarding $\mathrm{PGE}_{2}$ and $\mathrm{LTB}_{4}$ release and cAMP and cGMP level in human alveolar macrophages obtained from controls and COPD patients. Basal levels per five million control- respectively COPD alveolar macrophages: cAMP 1.2 and 1.0 pmole; cGMP 8.4 and 9.1 fmole; $P E_{2} 120$ and $63 \mathrm{pg}$ and $\mathrm{LTB}_{4}$ 19.2 and $14.8 \mathrm{pg}$. In both populations IBMX increased cAMP level by $55-93 \%$ and salbutamol+IBMX by $285-252 \%$. Except for the $61 \%$ rise in $\mathrm{LTB}_{4}$ release by salbutamol+IBMX the drugs hardly affected $\mathrm{PGE}_{2}$ and $\mathrm{LTB}_{4}$ release from control macrophages. In COPD alveolar macrophages, however, IBMX and IBMX+salbutamol largely reduced $\mathrm{PGE}_{2}$ release (63 vs $11 \mathrm{pg}$ per $10^{6}$ cells) but less efficiently increased LTB $_{4}$. In both macrophage populations sodium nitroprusside (SNP) substantially increased (3-4 fold) cGMP level but did not affect eicosanoid production. Present results indicate that drugs which enhance cAMP level decrease $\mathrm{PGE}_{2}$ release from COPD macrophages and stimulate the release of $\mathrm{LTB}_{4}$ a chemotactic mediator involved in bronchial inflammatory reactions.

Key Words: alveolar macrophages, cyclic AMP, eicosanoid release

Airway inflammation is a characteristic feature of both asthma and chronic obstructive pulmonary diseases (COPD) resulting from largely unknown pathophysiological events (1). Alveolar macrophages (AM) modulate the activity of other cells via the release of cytokines, prostaglandins, leukotrienes and PAF $(2,3)$. The released eicosanoids, notably $\mathrm{LTB}_{4}(4-5)$ and $\mathrm{PGE}_{2}$ (6) may affect via feedback mechanism(s) macrophage activity itself (7-9) or the activity of other cells (10). $\mathrm{LTB}_{4}$ for instance is chemotactic for mast cells (11), eosinophils (12) and

Corresponding author: Dr J.G.C. van Amsterdam, RIVM, PO Box 1, NL-3720 BA Bilthoven. 
neutrophils (13). Stimulated AM from asthmatic patients release larger amounts of inflammatory mediators than AM derived from healthy subjects $(14,15)$ though others did not confirm this (16). Release of lipid mediators (prostaglandins, leukotrienes and PAF) from AM may have important implications for the micro-environment of the bronchoalveolar compartment.

The modulatory effects of AM depend on various factors like basal intracellular cAMP level, state of priming and exposure to biologically active substances. Increase in intracellular cAMP level generally decreases cellular activity. For instance elevation of cAMP inhibits zymosanstimulated arachidonic acid release in monocytes (17) and the production of thromboxane $\mathrm{B}_{2}$ and $\mathrm{LTB}_{4}$ in elicited peritoneal macrophages (18). Whether in addition cGMP level is also of importance in the control of cellular activity is not well established. Zymosan elicits a rapid rise in both cAMP and cGMP formation (19) and muramyl dipeptide (20), sodium nitroprusside (19), and exogenous cGMP have been shown to enhance macrophage activity $(20,21)$. Others, however, do not observe macrophage activation by inducers of cGMP production (19).

The effect of bronchodilating drugs (salbutamol, sodium nitroprusside and theophylline-like compounds) are believed to be beneficial only. However, by changing intracellular cyclic nucleotide levels these drugs may in addition alter the functional activity of AM, known to be involved in airway inflammation.

\section{Materials and Methods}

Ten patients (female, age 25-40 yrs, mean age 31, all smokers, $>7$ pack years) hospitalised for obstetric purposes were studied. None of these subjects had a history of pulmonary disorders or received any medication two months prior to the study. Informed consent for bronchoalveolar lavage (BAL) was obtained. Alveolar cells were obtained by BAL under general anaesthesia using a fiberoptic bronchoscope. BAL fluids containing a total of $25-85 \cdot 10^{6}$ cells were subsequently kept on ice.

Lung tissue was obtained from 8 smoking ( $>10$ pack years) COPD patients with peripheral carcinoma (6 male, 2 female, mean age 51 years) who had undergone thoracotomy. According to the criteria of the American Thoracic Society all patients were diagnosed for COPD. Patients receiving beta-sympathomimetics or theophylline were excluded from the study. Mean FEV was $65.7 \%$, mean FVC was $87.3 \%$ (calculated from normal predicted value). Within 30 min after surgical resection tissue was immersed in ice-cold buffer. AM were recovered by in-vitro lavage of segments using a $20 \mathrm{ml}$ syringe.

BAL fluids were filtered through surgical gauze and centrifuged at $400 \mathrm{~g}\left(10 \mathrm{~min}, 4^{\circ} \mathrm{C}\right)$. The pellet was resuspended in Gey Balanced Salt Solution (GBSS), pH 7.4 and AM were purified by Ficoll-Isopaque centrifugation $\left(400 \mathrm{~g}, 30 \mathrm{~min}, 4^{\circ} \mathrm{C}\right.$ ) and the resultant $\mathrm{AM}$ layer was washed twice. May Grünwald Giemsa staining showed that the suspension contained approximately 96\% (control) and $86 \%$ (COPD) AM. Viability of the cells was at least $95 \%$. Cells were not further purified via culturing to avoid frustrated phagocytosis eliciting cell activation.

AM $\left(2.10^{6} \mathrm{ml}^{-1}\right)$ were incubated in GBSS buffer at $37^{\circ} \mathrm{C}$ for $60 \mathrm{~min}$ and drugs dissolved in GBSS. In some experiments cell suspensions were pre-incubated for $15 \mathrm{~min}$ with $10 \mu \mathrm{M}$ propranolol. Incubation was stopped by centrifugation $(1 \mathrm{~min}, 15,000 \mathrm{~g})$ and the supernatant was removed, freeze dried and stored at $-80^{\circ} \mathrm{C}$ for analysis of eicosanoids. The pellet was resuspended in $150 \mu \mathrm{l}$ Tris- $\mathrm{HCl}$ buffer ( $\mathrm{pH} \mathrm{7.4)}$ and boiled for $3 \mathrm{~min}$. $\mathrm{PGE}_{2}$ and $\mathrm{LTB}_{4}$ were assayed by ELISA. Detection limits for $\mathrm{PGE}_{2}$ and $\mathrm{LTB}_{4}$ were 3 and $1 \mathrm{pg} / \mathrm{ml}$. Cellular cyclic 
AMP was determined by radioimmunoassay using $\left[{ }^{3} \mathrm{H}\right]$ CAMP and an isolated binding protein (22). Cellular cGMP levels were determined by radioimmunoassay after acetylation (23).

Ficoll-Isopaque (Nycomed, Oslo, Norway); IBMX (isobutyl-methylxanthine, Janssen Chimica, Beerse, Belgium); salbutamol, sodium nitroprusside (SNP) and BSA (Sigma, St-Louis, USA); propranolol (Ciba-Geigy, Basel, Switzerland); ELISA kits for $\mathrm{PGE}_{2}$ and $\mathrm{LTB}_{4}$ (Cayman Chemical, Ann Arbor, USA); $\left[{ }^{3} \mathrm{H}\right]$ cAMP and $\left[{ }^{125} \mathrm{I}\right]$ succinyl-cGMP tyrosine methyl ester (Amersham International, Amersham, UK).

Data are expressed as means \pm s.e.mean. Statistical significance was evaluated by the MannWhitney $U$ test. A P value $<0.05$ was considered significant.

\section{$\underline{\text { Results }}$}

\section{Cellular composition of BAL and basal values of control macrophages}

Despite the use of different techniques to harvest broncholaveolar cells, cellular composition may be compared (24). Analysis of the cellular composition of BAL fluids showed large differences between controls and COPD subjects. BAL fluids of controls contained mainly AM $(95 \%)$ and some lymphocytes $(3.6 \%)$. In BAL fluids obtained from COPD patients considerable numbers of eosinophils $(7.4 \%)$, neutrophils $(14.4 \%)$ and lymphocytes $(10.6 \%)$ were present.

Basal values and effects of drugs on cyclic nucleotide levels and eicosanoid release in control AM are denoted in Table 1. In controls, basal cAMP and cGMP level per $10^{6} \mathrm{AM}$ was 1.4 pmole and 8.4 fmole, reflecting a 160 -fold difference in concentration.

Levels of cyclic nucleotides and eicosanoid release in control macrophages

In the presence of the nonselective phosphodiesterase inhibitor IBMX CAMP and cGMP levels rose to respectively $193 \%$ and $155 \%$ of basal level (cf. Table 1). Eicosanoid release from AM was only slightly though significantly affected by IBMX: per $10^{6} \mathrm{AM}^{\mathrm{PGE}} \mathrm{E}_{2}$ release decreased from $120 \mathrm{pg}$ to $90 \mathrm{pg}$ and $\mathrm{LTB}_{4}$ release increased from 19 to $24 \mathrm{pg}$.

\section{TABLE 1}

Cyclic nucleotide levels and eicosanoid release in control human AM. Data are expressed as mean \pm s.e.mean from 8-10 duplicate experiments. Salb.: salbutamol; SNP: sodium nitroprusside.

\section{pmole cAMP $/ 10^{6} \mathrm{AM}$ fmole cGMP $/ 10^{6} \mathrm{AM}$ pg PGE $/ 10^{6} \mathrm{AM}$ pg LTB $/ 10^{6} \mathrm{AM}$}

\begin{tabular}{llccc} 
saline & $1.4 \pm 0.1$ & $8.4 \pm 1.1$ & $120 \pm 5$ & $19.2 \pm 4.2$ \\
$1 \mathrm{mM}$ IBMX & $2.7 \pm 0.3^{*}$ & $13.0 \pm 1.7^{*}$ & $90 \pm 6^{*}$ & $24.2 \pm 3.5^{*}$ \\
$1 \mathrm{mM}$ IBMX + & $4.0 \pm 0.4^{* *}$ & $13.3 \pm 2.3$ & $80 \pm 3$ & $30.4 \pm 3.1^{* *}$ \\
$10 \mu \mathrm{M} \mathrm{salb}$ & & & & \\
$1 \mathrm{mM}$ IBMX + & $2.2 \pm 0.3^{\mathrm{Ns}}$ & $24.3 \pm 2.9^{* *}$ & $98 \pm 6$ & $25.4 \pm 5.1$ \\
$1 \mathrm{mM} \mathrm{SNP}$ & & & & \\
\hline
\end{tabular}

${ }^{*} \mathrm{P}<0.05$ vs saline; ${ }^{* *} \mathrm{P}<0.05$ vs IBMX alone; ${ }^{\text {Ns }}$ non-significant vs IBMX alone. 
TABLE 2

Cyclic nucleotide levels and eicosanoid release in AM from COPD patients. Data are expressed as mean \pm s.e.mean from 7-8 duplicate experiments. Salb.: salbutamol. SNP: sodium nitroprusside.

pmole cAMP $/ 10^{6} \mathrm{AM}$ fmole cGMP $/ 10^{6} \mathrm{AM}$ pg PGE $/ 10^{6} \mathrm{AM}$ pg LTB $/ 10^{6} \mathrm{AM}$

$\begin{array}{llccc}\text { saline } & 1.0 \pm 0.1^{\dagger} & 9.1 \pm 1.3 & 63 \pm 9 & 14.8 \pm 0.5 \\ 1 \mathrm{mM} \text { IBMX } & 1.5 \pm 0.3^{*} & 16.0 \pm 1.9^{*} & 11 \pm 6^{*} & 18.3 \pm 2.0^{*} \\ 1 \mathrm{mM} \text { IBMX }+ & 2.5 \pm 0.3^{* *} & 13.6 \pm 2.2 & 9 \pm 3 & 16.2 \pm 0.3 \\ 10 \mu \mathrm{M} \text { salb. } & & & & \\ 1 \mathrm{mM} \text { IBMX }+ & 1.5 \pm 0.2 & 37.4 \pm 2.4^{* *, 3} & 6 \pm 3 & 17.2 \pm 0.8 \\ 1 \mathrm{mM} \mathrm{SNP} & & & & \end{array}$

${ }^{\dagger} \mathrm{P}<0.05$ compared to control $\mathrm{AM} ;{ }^{*} \mathrm{P}<0.05$ vs saline; ${ }^{* *} \mathrm{P}<0.05$ vs IBMX alone; ${ }^{3}$ difference in effect of SNP between control-AM and COPD-AM is not significant.

The combination of IBMX with the selective beta - -sympathomimetic salbutamol enhanced intracellular cAMP level more efficiently than IBMX alone (185\% increase), but compared to IBMX PGE 2 release was hardly further inhibited. Considering $\mathrm{LTB}_{4}$ release, however, salbutamol+IBMX was some two-fold more effective than IBMX alone (30.4 vs 24.2). Propranolol $(10 \mu \mathrm{M})$ completely blocked the salbutamol effects (not shown). Sodium nitroprusside (SNP) substantially increases cellular cGMP concentration (additional 134\%) but does not affect cAMP content or eicosanoid release.

Levels of cyclic nucleotides and eicosanoid release in AM from COPD patients

Table 2 shows that untreated AM from COPD patients (refered as COPD-AM) contained less cAMP (-29\%) and released considerable less $\mathrm{PGE}_{2}$ and $\mathrm{LTB}_{4}$ compared to control AM $(50 \%$ respectively $70 \%$ ). The drugs IBMX and salbutamol enhanced cyclic nucleotide levels roughly to the same extent as in control AM. However, compared to control AM the reduction in $\mathrm{PGE}_{2}$ release was much larger (83\% vs $21 \%$ ) while $\mathrm{LTB}_{4}$ release was slightly enhanced $(24 \%)$. Salbutamol induced in COPD-AM a further increase in cAMP level (additional $+102 \%$ compared to IBMX) which was not related to additional changes in $\mathrm{PGE}_{2}-$ or $\mathrm{LTB}_{4}$ release. SNP showed similar responses in COPD-AM and control AM.

\section{Discussion}

Considering basal values for cAMP and eicosanoid release some interesting differences between the macrophage populations of controls and COPD patients are observed. Others observe about 50-fold lower amounts of eicosanoid released which may be due to the purification technique used (adherence/culturing) enhancing 'basal' activation state due to frustated phagocytosis (25). In this process eicosanoid release rises, peaks, exhausts and returns to some resting level. Thus it is conceivable that subsequent exposure induces smaller amounts of released eicosanoids. Different results may also be obtained when the metabolism of a nonendogenous pool of tritiated arachidonic acid is determined.

The present study compares COPD-AM with control AM from patients with no history of 
pulmonary disorder. Both groups of AM were obtained from smokers only to allow good comparison as it is generally known that smoking impairs certain AM functions including eicosanoid production (26). In contrast to control-AM, COPD-AM are recovered from patients with a pulmonary environment characterized by frequent unspecified inflammations (note the considerable number of inflammatory cells in the BAL of COPD patients). In addition, COPD$A M$ are obtained from a rather heterogeneous group of COPD patients consuming a variety of drugs. So COPD-AM differ predominantly from control-AM by their origine from an inflammatory environment which probably renders COPD-AM more elicited than control-AM.

Compared to control-AM, COPD-AM show significantly lower basal level in cAMP and PGE and $\mathrm{LTB}_{4}$ release and behave quite differently regarding induced eicosanoid release. Peritoneal macrophages obtained during peritoneal inflammation likewise showed lower basal cAMP level and $\mathrm{PGE}_{2}$ release compared to macrophages collected from patients without such complications (27). Drug-induced increases in cellular cAMP level was related to decreased $P_{G E}$ and a slight increase in $\mathrm{LTB}_{4}$ release. These results are only partly comparable with previous results obtained in activated (elicited, cultured or primed) macrophages showing that elevation of cAMP level inhibited both $\mathrm{PGE}_{2}$ and $\mathrm{LTB}_{4}$ release (e.g. 18).

Interestingly, IBMX induces in the two AM populations a similar increase in cAMP level but affects $\mathrm{PGE}_{2}$ release in COPD-AM to a much larger extent compared to control AM (decrease respectively 83 and $17 \%$ ). Both macrophage populations show, however, a comparable increase in $\mathrm{LTB}_{4}$ release in response to $\mathrm{IBMX}$.

We suggest that in control $\mathrm{AM}$ the reduction of free arachidonic acid metabolism to $\mathrm{PGE}_{2}$ results in a higher availability of the common substrate (free arachidonic acid) for leukotriene synthesis by 5-lipoxygenase. Simultaneous down-regulation of cyclooxygenase and enhanced 5lipoxygenase activity has recently been observed by Mackenzie et al. (25) in macrophages exposed to calcium ionophore. The suggested inhibition of phospholipase $A_{2}$ and release of arachidonic acid from phospholipids by elevated cAMP (28) may only explain the decrease in $\mathrm{PGE}_{2}$ release but not the change in $\mathrm{LTB}_{4}$ release.

In both control AM and COPD-AM enhancement of cGMP level is not related to either $\mathrm{PGE}_{2}$ or $\mathrm{LTB}_{4}$ release indicating that the cytosolic pool of cGMP is not involved in the regulation of eicosanoid release from $\mathbf{A M}$.

Due to their bronchodilating proporties the xanthine derivative theophylline and beta 2 -sympathomimetics are frequently used in the treatment of asthma and COPD. Present results indicate that these drugs in addition modulate eicosanoid release from AM which may have important implications for the micro-environment in bronchoalveolar compartment.

\section{Acknowledgements}

We thank H.C. Raatgeep for technical and the Dutch Asthma Fund for financial support.

\section{$\underline{\text { References }}$}

1. K.F. CHUNG, Thorax, 41 657-662 (1986).

2. B. ARNOUX, D. DUVAL and J. BENVENISTE, Eur. J. Clin. Invest. 10 437-441 (1980).

3. Y. SIBILLE and H.Y. REYNOLDS, Am. Rev. Respir. Dis., 141 471-501 (1990). 
4. T.R. MARTIN, L.C. ALTMAN, R.K. ALBERT and W.R. HENDERSON, Am. Rev. Respir. Dis., 129 106-111 (1984).

5. T. BIGBY and M.J. HOLTZMAN, J. Immunol., 138 1546-1550 (1987).

6. P. GODARD, J. CHAINTREUIL, M. DAMON, M. COUPE, O. FLANDRE, A. CRASTES DE PAULET and F.B. MICHEL, J. Allergy Clin. Immunol., 70 88-93 (1982).

7. S.L. KUNKEL, S.W. CHENSUE, S.H. Phan, J. Immunol., 136 186-192 (1986).

8. M. MONICK, J. GLAZIER and G.W. HUNNINGHAKE, Am. Rev. Respir. Dis., $13572-$ 77 (1987).

9. M. ROLA-PLESZCZYNSKI and I. LEMAIRE, J. Immunol., 135 3958-3960 (1985).

10. P.J. BARNES, K. FAN CHUNG and C.P. PAGE, Pharmacol. Rev., 40 49-84 (1988).

11. M. KALINER, J. Allergy Clin. Immunol., 83 510-520 (1989).

12. J.G.R. DE MONCHY, H.F. KAUFFMAN, P. VENGE, G.H. KOETER, H.M. JANSEN, H.J. SLUITER and K. DE VRIES, Am. Rev. Respir. Dis., 131 373-376 (1985).

13. W.J. METZGER, H.B. RICHARDSON, K. WORDEN, M. MONICK and G.W. HUNNINGHAKE, Chest, $\underline{89}$ 477-483 (1986).

14. M. DAMON, C. CHAVIS, J.P. DAURES, A. CRASTES DE PAULET, F.B. MICHEL and Ph. GODARD, Eur. Respir. J., 2 202-209 (1989).

15. M. JOSEPH, A.B. TONNEL, A. CAPRON and C. VOISIN, Clin. Exp. Immunol., 40 416422 (1990).

16. M.S. BALTER, G.B. TOEWS and M. PETERS-GOLDEN, Am. Rev. Resp. Dis $1381134-$ 1140 (1988).

17. R.W. GODFREY, R.M. MANZI, D.E. GENARRO and S.T. HOFFSTEIN, J. Cell Physiol., 131 384-392 (1987).

18. G.R. ELLIOTT, A.P.M. LAUWEN and I.L. BONTA, Br. J. Pharmacol., 96 265-270 (1989).

19. S.D. ROHRER and P. ATKINSON, J. Reticul. Soc. 28 343-356 (1980).

20. T.E. SCHINDLER, R.G. COFFEY and W.J. HADDEN, Int. J. Immunopharmacol. $\underline{8}$ 487498 (1986).

21. H. RENZ, J.H. GONG, A. SCHMIDT, M. NAIN and D. GEMSA, J. Immunol. 14 23882393 (1988).

22. I.L. BONTA, M.P.J. ADOLFS and M.W.J.A. FIEREN, Int. J. Immunopharmacol., $\underline{6}$ 547555 (1984).

23. J.F. HARPER and G. BROOKER, J. Cyclic Nucleotide Res., 1 207-218 (1975).

24. J.E. HOBSON, J.L. WRIGHT, B.R. WIGGS and J.C. Hogg, Resp., 50 1-8 (1987).

25. R. MACKENZIE, G.A. COLES, N. TOPLEY, W.S. POWELL and J.D. WILlIAMS, Immunology 96 648-654 (1992).

26. M. LAVIOLETTE, J. CHANG and P.J. NEWCOMBE, Am. Rev. Respir. Dis. 124 397-401 (1981).

27. M.P.J. ADOLFS, M.W.J.A. FIEREN and I.L. BONTA, Prostagl. Leukotr. Med. 18 217226 (1985).

28. C. KADIRI, J. MASLIAH, M. BACHELET, B.B. VARGAFTIG and G. BÉRÉZIAT, J. Cellular Biochem. 40 157-164 (1989). 